\title{
Francisco Iglésias e o curso de geografia e história da Faculdade de Filosofia de Minas Gerais (década de 1940)*
}

\author{
Francisco Iglésias and the undergraduate course of geography and \\ history at the School of Philosophy of Minas Gerais (1940's)
}

\author{
Alessandra Soares Santos \\ alessandrast@ufmg.br \\ Doutoranda \\ Universidade Federal de Minas Gerais \\ Rua Tenente Garro, 627/301 - Santa Efigênia \\ 30240-360 - Belo Horizonte - MG \\ Brasil
}

\begin{abstract}
Resumo
O artigo busca reaver uma parte da dinâmica histórica que levou à disciplinarização do conhecimento histórico como uma ciência social no interior das instituições de ensino superior através do estudo dos anos de formação do historiador Francisco Iglésias no curso de geografia e história da Faculdade de Filosofia de Minas Gerais (FAFI) entre 1942 e 1945. Para além da análise dos textos normativos que regularam a organização curricular e didática do curso, verificamos algumas das práticas utilizadas nas salas de aula frequentadas por Francisco Iglésias percebendo a faculdade em seu funcionamento interno. Concluímos que a concepção de história que orientou a elaboração das sistematizações do ensino nesta instituição valorizou a dimensão cultural dos 104 acontecimentos em detrimento do projeto de história nacional afeito à exaltação de grandes nomes e datas, supostamente imposto pelas diretrizes da Faculdade Nacional de Filosofia (FNFi).
\end{abstract}

\section{Palavras-chave}

Conhecimento histórico; Ensino de história; Francisco Iglésias.

\begin{abstract}
The article seeks to explore the institutionalization of historical knowledge through the analysis of the undergraduate course of Geography and History of the School of Philosophy of Minas Gerais (FAFI) by examining the formative years of the historian Francisco Iglésias between 1942 and 1945. For this purpose, we use not only the normative regulations of the course's curricular and didactical organization, but we also examine some of the practices of the chairs attended by Francisco Iglésias, in order to grasp the internal workings of the School. We conclude that the conception of history that guided the production of teaching systematics at the institution prized the cultural dimension of the events in detriment of the project of national history focused on the exaltation of heroes and dates, supposedly imposed by the guidelines of the National School of Philosophy (FNFi).
\end{abstract}

\section{Keywords}

Historical knowledge; History teaching; Francisco Iglésias.

Recebido em: 7/11/2012

Aprovado em: 8/2/2013

* Pesquisa financiada pela CAPES. 


\section{A historiografia universitária em questão}

Os fundamentos que levam a história a se disciplinar e a manter o princípio de cientificidade que autoriza o seu discurso não são "naturais", mas resultado de uma dinâmica histórica que pode ser investigada com o objetivo de perceber a nem sempre óbvia historicidade destas práticas intelectuais. Como um princípio de controle da produção de um discurso, uma disciplina se define, conforme Foucault, "por um domínio de objetos, um conjunto de métodos, um corpus de proposições consideradas verdadeiras, um jogo de regras e de definições, de técnicas e de instrumentos" (FOUCAULT 2003, p. 30-31), constituindo um sistema anônimo a disposição de qualquer um que queira ou possa se servir dele. O pertencimento a uma instituição social é o suporte que possibilita o controle da linguagem pela disciplina através da seleção dos objetos observáveis, da imposição de uma função ao sujeito cognoscente e do acesso a determinadas técnicas de conhecimento (CERTEAU 2008). O "regime de verdade" assim constituído, diferente segundo o tempo e o lugar que o determina, impõe uma ordem ao discurso que se apoia em um sistema de exclusão: ele limita os contornos de um grupo e de um saber.

Mas na rotina do ofício dos historiadores vinculados às instituições universitárias contemporâneas raramente se questiona os mecanismos responsáveis pela estabilização dos princípios que controlam a produção do discurso historiográfico que participamos. A submissão aos critérios disciplinares impostos pela instituição no qual atuamos não implica o reconhecimento de sua construção histórica, pois o movimento que determina as ideias que compartilhamos é o mesmo que organiza a sociedade em que vivemos (CERTEAU

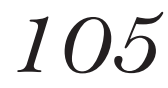
2008). Embora estejamos acostumados a localizar historicamente as experiências do passado, aprendemos a recalcar os sistemas sociais, econômicos e simbólicos nos quais inevitavelmente estamos situados em obediência às pretensões de cientificidade guardadas pela disciplinarização da prática historiográfica acadêmica. Esta sublimação, tacitamente exigida, transforma todo interesse científico em um "interesse desinteressado", gratuito. Bourdieu o classificou como uma forma particular de illusio (jogo): admitimos que o jogo mereça ser jogado, incorporamos suas regras e participamos do sentido deste jogo como se ele justificasse por si mesmo todo nosso investimento (BOURDIEU 2004). Este illusio explica em parte porque só recentemente os historiadores começaram a transformar os processos e os resultados da institucionalização dos cursos de história nas universidades brasileiras, datados na década de 1930, em objetos de pesquisa histórica.

Para que pudéssemos dar inteligibilidade às condições pretéritas de produção do discurso histórico no interior do mesmo campo em que atuamos foi necessário recomeçar o jogo efetuando um corte "inaugurador" das práticas historiográficas do presente. A baliza que sacraliza a nossa própria prática e parece querer resguardá-la do princípio da historicidade foi demarcada pela emergência dos cursos de pós-graduação em história nos anos 1960. A "verdadeira" historiografia universitária brasileira, supostamente mais "profissional" e mais comprometida com os princípios da legitimidade científica teria nascido com as 
iniciativas institucionais voltadas para o aperfeiçoamento dos docentes do ensino superior e que resultaram na implantação da pós-graduação. Diehl chamou esse momento de "(re)institucionalização do saber histórico", ressaltando o caráter fundador de um regime de verdade historiográfica distinto (DIEHL 1999). A criação de uma nova instituição histórica dentro de outra já existente, de um subgrupo responsável pelo controle da seleção e da qualificação dos sujeitos autorizados a falar em nome da historiografia universitária, foi naturalmente acompanhada pela construção de uma identidade pautada pela valorização da diferença epistemológica entre estes dois grupos internos.

As histórias da historiografia produzidas a partir deste marco tiveram uma função importante na afirmação da posição ocupada pela pós-graduação. Obras e autores foram selecionados e conectados entre si em função da similitude de suas estratégias com aquela praticada pelos novos historiadores. Elas acabaram traduzindo a ideia da "sobrevivência do mais preparado", conforme destacou Blanke ao analisar as histórias da disciplina com função afirmativa, transformando posições político-científicas em explicações sistemáticas e paradigmáticas (BLANKE 2006). Como exemplo, podemos citar o uso que se fez do famoso prefácio de Antonio Candido à quinta edição de Raízes do Brasil, escrito em 1967. Este prefácio foi apropriado de forma a justificar a canonização de três livros do pensamento social brasileiro - Casa grande \& senzala, de Gilberto Freyre; Raízes do Brasil, de Sérgio Buarque de Holanda; e Formação do Brasil contemporâneo, de Caio Prado Júnior - não só como inauguradores da "moderna historiografia 106 brasileira" na década de 1930, mas também como representantes exclusivos da profissionalização do historiador no espaço universitário pelo menos até a década de 1960. Não obstante o valor das obras mencionadas, o desdobramento da construção desta tríade sagrada foi a interpretação de obras anteriores como um conjunto homogêneo de produções "oficiais", "ideológicas" ou "positivistas" pertencentes à tradição do IHGB, enquanto obras posteriores foram ofuscadas pela ideia de que a "moderna" historiografia brasileira estaria limitada àqueles livros consagrados (FRANZINI; GONTIJO 2009). Naturalmente, como observou Blanke, "qualquer posição teórica que quer sobreviver requer tradições positivas" (BLANKE 2006, p. 33-34), mas a história da historiografia, conforme advertiu o mesmo autor, precisa ter uma atitude cética em relação a elas, uma "rebeldia" capaz de produzir uma história disciplinar socialmente informada.

Ainda que a diversificação dos estudos historiográficos empreendidos a partir da década de 1990 tenha mostrado que os fundamentos discursivos da historiografia não são necessariamente pautados pelo afastamento ou pela filiação a modelos epistemológicos dados, recobrando uma herança ou impondo uma tradição, mas são construídos em sintonia com as disposições intelectuais do presente, persistem esforços para ocultar as disputas inerentes aos jogos sociais que orientam estas construções. O exame escrupuloso das produções históricas anteriores e a retificação das versões do passado de acordo com a pretensão científica da normatização disciplinar vigente ainda restringem a história da historiografia a um "laboratório de epistemologia histórica" (WEHLING 2006), uma atividade complementar ao conhecimento histórico que teria como 
objetivo arrolar as teorias e os problemas aplicados a uma crítica da razão científica e promover o refinamento das pesquisas.

Este procedimento moderno de hierarquização dos esforços para alcançar a cientificidade e a objetividade no tratamento do passado desgastou a consciência da relatividade histórica da própria historiografia e promoveu a consolidação do mito de sua formação progressiva (ARAUJO 2011). Parte significativa dos trabalhos feitos nesse campo acabou ignorando as dinâmicas históricas que levaram a historiografia a se disciplinar, a se transformar numa ciência social e a fundamentar seus princípios de autoridade. As histórias da historiografia assim orientadas tenderam a classificar as produções históricas entre "inovadoras" ou "tradicionais"; "profissionais" ou "amadoras"; "científicas" ou "ideológicas" conforme o afastamento ou a aproximação em relação ao modelo historiográfico em vigor. Mas conforme Fernando Novais bem observou, "às vezes, o que se quer dizer com tradicional é que, simplesmente, tradicionais são os outros" (NOVAIS 1990, p. 108). Além de incorrer no risco de ignorar que o "profissional" do conhecimento histórico era uma condição requerida desde o século XIX e que as disputas entre o "amadorismo" e o "profissionalismo" marcaram as tensões do ofício desde então (GUIMARÃES 2002), o novo corte inaugurador da historiografia universitária oculta que, no interior da própria universidade, sua reivindicação antecedeu a pós-graduação.

É, portanto, contra o apagamento dos vestígios que inscrevem os procedimentos de disciplinarização do conhecimento no mundo histórico que voltamos a atenção para os processos de sua institucionalização. Acompanhando a inserção acadêmica de Francisco Iglésias como discente no curso de geografia e história da Faculdade de Filosofia de Minas Gerais entre 1942 e 1945, pretendemos conhecer uma parte da dinâmica disciplinar da história, visto que a discência de Francisco Iglésias coincidiu com o momento de institucionalização do curso no estado. A partir da análise de um conjunto documental no qual as disposições legais tiveram que disputar espaço com os documentos produzidos pelos próprios professores e alunos, como os diários de classes e as provas, abrimos uma perspectiva que nos permitiu relativizar as normas que definiram os conhecimentos a ensinar e condutas a inculcar no âmbito do ensino superior de história através da sua problematização (JULIA 2001).

\section{A organização e o clima intelectual da Faculdade de Filosofia de Minas Gerais}

A constituição da Faculdade de Filosofia (FAFI) conta com poucos trabalhos que oferecem conhecimento sobre sua história e sua dinâmica acadêmica. A ênfase no modelo paulista de autonomia acadêmica e intelectual parece ter atribuído um caráter de incompletude e insuficiência às outras experiências acadêmico-universitárias, desvalorizando-as e desestimulando até mesmo sua tomada como objeto histórico. A ideia de que a criação da Faculdade Nacional de Filosofia (FNFi), em 1939, fez parte de um projeto para padronizar as demais faculdades de filosofia fundadas nas décadas de 1930 e 1940, também parece ter subestimado as características específicas que revelam as dificuldades e as indecisões inerentes a cada um dos processos de institucionalização universitária. 
No caso da FAFI, o desencorajamento das pesquisas sobre seu desenvolvimento histórico deve ser atribuído também à ausência quase completa de organização dos seus arquivos. O Setor de Registro e Arquivo Acadêmico Permanente da Graduação da Faculdade de Filosofia e Ciências Humanas da UFMG guarda documentos produzidos pela instituição desde 1939. São relatórios, balancetes, currículos, diários, atas de reuniões, atas de exames, provas e registros variados da administração e do corpo docente e discente da instituição. É um acervo de enorme valor histórico que se encontra, até agora, privado de ações que garantam sua preservação, sua organização e sua adequada disponibilização para o pesquisador. Diante dessas condições, as informações que levantamos aqui não pretendem nem poderiam esgotar o tema da criação da FAFI e de sua dinâmica acadêmica, mas esperamos que sejam suficientes para mostrar que a nova situação social que ela engendrou não deixou imune nem o modo de trabalhar, nem o tipo de discurso de seus diplomados, entre os quais se encontrava Francisco Iglésias.

O histórico oficial da Faculdade de Filosofia da Universidade de Minas Gerais publicado no Anuário de 1939 a 1953 confere aos professores vinculados ao Instituto Ítalo-Mineiro Guglielmo Marconi a iniciativa e a organização da instituição. Os professores do Colégio Marconi teriam cuidado de todo o processo de fundação da FAFI, desde o convite dos "mais conspícuos representantes do magistério, das ciências e das letras de Belo Horizonte" para uma reunião preliminar preparatória até o estudo da legislação vigente sobre o funcionamento das escolas de ensino superior e sobre a estrutura da instituição-modelo - a FNFi, organizada naquele mesmo ano. A assembleia fundadora da FAFI, reunida no salão nobre do Colégio Marconi na simbólica data de 21 de abril de 1939, teria realizado a sessão magna de fundação da instituição e, a partir daí, a escolha de seu primeiro diretor - o professor das Escolas de Engenharia de Ouro Preto e de Belo Horizonte, Lúcio José dos Santos - e de seu Conselho Técnico Administrativo, responsável pela elaboração dos estatutos e do regimento interno da nova instituição, pela organização do corpo docente e discente e pela regularização dos cursos junto ao Conselho Nacional de Ensino do Ministério da Educação e Saúde (ANUÁRIO 1939-1953). O processo burocrático inerente à autorização de funcionamento da FAFI, entretanto, atrasou em mais de um ano o início de suas atividades. Concedida em 1941, ela era provisória e não implicava o reconhecimento oficial da instituição, o que só foi feito em 1946 mediante a satisfação de uma série de condições financeiras, administrativas e didáticas.

A história oficial da FAFI recorreu, como não poderia deixar de ser, aos indivíduos que estabeleceram as relações constitutivas deste espaço institucional para glorificar suas ações. Conforme ficou registrado, os professores-fundadores foram referidos como "os desprendidos e bravos mestres que a criaram" e que teriam se submetido a "longas e extenuantes atividades" com "idealismo e generosidade" e garantido "milagrosamente" o funcionamento da Faculdade que, "não fora a extraordinária abnegação e o sacrifício ingente de seus professores, que por quase um decênio a serviram, sem outro interesse que não o da alta cultura, não existiria ela hoje" (ANUÁRIO 1939-1953, p. 17). 
Por um lado é preciso ponderar que embora a FAFI tenha nascido e se mantido através de iniciativas particulares, sua expectativa sempre foi se incorporar à UMG, o que significava transformar seus professores-fundadores em catedráticos na nova organização. Por outro, o cuidado para não endossar a mitificação daqueles professores não deve afastar a necessidade de conhecê-los enquanto indivíduos dotados de um capital específico com o objetivo de compreender as formas de poder que operaram sobre o conjunto das relações constitutivas daquele espaço, visto que a soma destes atributos é que define o peso social de uma instituição (BOURDIEU 2011). Cabe reconhecer, ainda, que esse capital foi ao mesmo tempo usado e enriquecido pela ação em favor da criação e da manutenção da FAFI, pois o envolvimento desses professores com uma instituição de ensino superior os posicionava numa escala acima na hierarquia do espaço cultural que buscava valorizar a ciência e as letras produzidas a partir da universidade.

A tensão entre as formas de poder inerentes à organização das faculdades de filosofia - o poder político e o poder científico (BOURDIEU 2011) - esteve presente desde os primeiros anos de funcionamento da FAFI. Por um lado seus professores-fundadores estavam respaldados pelo capital intelectual que acumularam nas atividades que exerceram no campo cultural de Belo Horizonte durante vários anos. A notoriedade deles é que resguardava a legitimidade intelectual e científica da instituição. A formação e a trajetória profissional desses docentes - ainda que carentes de uma preparação formal para o magistério - cumpriram plenamente as condições impostas pelo regulamento de funcionamento dos estabelecimentos de ensino superior que exigia que fosse demonstrada a capacidade moral e técnica dos professores. Um relatório elaborado em 1945 para a obtenção do reconhecimento da nova instituição atestava que aqueles intelectuais eram "conhecidos no Brasil inteiro pelo renome alcançado nas ciências e letras do país" e que a comprovação de seus títulos em "fichas individuais em que se expõe e assinala o curso secundário e superior de cada didata, [enumerando] os seus títulos, trabalhos, diplomas, funções e cursos de especialização" não deixava dúvidas quanto à capacidade de cada um para exercer a função de magistério no ensino superior. ${ }^{1}$

Por outro lado havia a desconfiança de que alguns deles, enquanto partícipes das estruturas mais fundamentais da ordem social, estivessem em desacordo com a função de "transmitir a cultura legítima", outro dos encargos da instituição, devido às estreitas relações com uma cultura exterior, a italiana. Apesar da proximidade do governo brasileiro com os países do Eixo, a Segunda Guerra Mundial impunha atenção a qualquer influência externa naquele momento. A participação da Casa d'Itália, através do Instituto Marconi, na criação e na manutenção da FAFI, era percebida por alguns críticos e articulistas da imprensa como a realização dos propósitos educacionais das instituições italianas em Belo Horizonte. ${ }^{2}$

\footnotetext{
${ }^{1}$ Relatório de Reconhecimento da Faculdade de Filosofia de Minas Gerais, 1945. Setor de Registro e Arquivo Acadêmico Permanente da Graduação da FAFICH/UFMG.

2 Um artigo publicado no jornal "Estado de Minas" em 1941, no qual o autor analisa de forma irônica a permanência do "sentimento de italianidade" e de respeito ao fascismo na educação realizada na cidade,
} 
Se a relação da nova faculdade com a entidade de imigrantes da Casa d'Itália garantia o cumprimento das principais exigências do decreto federal para o funcionamento das instituições de ensino superior, visto que a própria manutenção financeira da FAFI estava vinculada a ela, também acabou sendo o maior empecilho para seu reconhecimento junto ao Conselho Nacional de Educação do Ministério da Educação e Saúde. O desenrolar da guerra acabou afetando as relações da Casa d'Itália com a FAFI, gerando uma relação incômoda que resultou na substituição do antigo diretor e na aceleração do processo de sua transferência para o prédio da Escola Normal com o apoio do Governo do Estado, ainda que a efetiva incorporação da Faculdade de Filosofia pela Universidade de Minas Gerais (UMG) só tenha se efetivado em 1948, um ano antes de sua federalização (HADDAD 1988).

Concomitante ao cumprimento das exigências burocráticas para o reconhecimento oficial, os membros FAFI investiram na consolidação da sua unidade intelectual. A construção da identidade institucional enquanto uma comunidade científica e cultural buscou se legitimar tanto no âmbito da universidade, quanto na sua relação com o contexto cultural mais amplo da cidade. No espaço acadêmico, a FAFI se justificava a partir da própria ideia de universidade que então circulava. A concepção de universidade que estava sendo debatida na época, inspirada no modelo humboldtiano, endossava a perspectiva de se criar uma instituição que participasse da lógica universitária, mesmo que ainda não integrada a ela. A ideia da "universidade moderna" colocava as faculdades de

110 Filosofia numa posição central dentro da estrutura universitária, pois atribuía às faculdades de Filosofia a justificação da importância da ciência para a cultura e a sociedade em geral através da reflexão filosófica que promoveriam. Através delas, seria possível garantir a unidade na diversidade das disciplinas científicas - a ideia da uni-versidade -, pois elas é que fundamentariam a reflexão sobre a relação do sujeito do conhecimento com ele próprio (HABERMAS 1987). A partir daí a ideia da "liberdade acadêmica" e do "saber desinteressado" começou a se impor ao argumento da profissionalização nos discursos de legitimação da institucionalização universitária.

A concepção de que as faculdades de filosofia deteriam uma posição central no interior das universidades começou não só a ser compartilhada pela intelectualidade brasileira, como a justificar a hierarquização das instituições existentes. Segundo Roiz, que analisa os discursos de Fernando de Azevedo e Júlio de Mesquita Filho sobre a fundação da Universidade de São Paulo (USP), entre as décadas de 1930 e 1950 houve um esforço para consolidar uma memória coletiva sobre os acontecimentos que viabilizaram a fundação desta universidade com o objetivo de diferenciar a sua Faculdade de Filosofia,

atestou como essa influência foi considerada significativa e suspeita: "A educação primária é feita no "Grupo Escolar" que tem o nome de Benito Mussolini. Basta este nome para você ver que o ensino aqui é insuspeito e não pode causar receio de desvirtuamento do espírito de nossos filhos. Esta escola funciona na Casa d'Itália. Faltava-nos o ginásio, mas nossos conacionais fascistas não mediram sacrifícios e temos um excelente estabelecimento que se chama Ginásio Guglielmo Marconi [...] os nossos conacionais, sempre vigilantes, promoveram a criação aqui de uma Faculdade de Filosofia, sob os auspícios do Instituto Guglielmo Marconi e funciona lá, numa instalação soberba (Carta à Giuseppe. Estado de Minas, Belo Horizonte, 20 de junho de 1941 apud HADDAD 1988, p. 88) 
Ciências e Letras de instituições similares criadas no período (ROIZ 2009). A partir da enorme ressonância desse discurso, a concepção de uma "verdadeira universidade" seria apenas aquela que teria conseguido superar o mero agrupamento de unidades de ensino superior através de uma faculdade de Filosofia criada simultaneamente ao seu nascimento. Naquele momento, a USP era a única que atendia a este requisito. A força desse discurso pode ser notada pela utilização, ainda frequente na historiografia brasileira sobre educação, de expressões tais como "espírito antiuniversitário" ou "escola profissionalizante" para se referir às instituições universitárias do Rio de Janeiro e de Minas Gerais nas décadas de 1920 e 1930, por exemplo, como se houvesse uma ideia genuína do que deveria ser a universidade brasileira e como se esta ideia estivesse sendo guardada pela USP.

Mas avaliar historicamente uma instituição a partir de sua distância em relação a uma organização universitária supostamente modelar é reduzir a variedade dos processos históricos e ignorar cada uma das especificidades dos lugares acadêmico-institucionais. Como notou Habermas, o tipo de concepção que vê na ideia da universidade moderna um projeto de materialização de uma forma de vida ideal parte de uma instância universal que é anterior à diversidade das formas de vida sociais. Ela pressupõe que seus membros tenham uma forma de pensar comum, pois compartilham princípios culturais resultantes de todas as configurações do espírito objetivo. Esta concepção de universidade foi herdada por várias gerações de intelectuais como o conceito de "verdadeira universidade", ainda que aquela perspectiva idealista tenha atribuído à universidade uma força de totalização que desde logo se revelou uma exigência que ela não poderia corresponder.

Mas, como observou o mesmo autor, "mal andaria a universidade se a consciência de si como corpo assentasse em qualquer coisa como um modelo normativo: as ideias, assim como vêm, assim se vão" (HABERMAS 1987, p. 128). É preciso reconhecer que aquela ideia de universidade é parte integrante de um paradigma da modernidade, cuja crise não pode deixar de acarretar a crise da própria ideia da universidade moderna. Abordar historicamente a construção desse modelo através de seus múltiplos aspectos é, pois, uma tarefa necessária para tornar mais complexas as reflexões sobre este tema específico, mas também sobre o próprio conhecimento histórico produzido na universidade.

$O$ fato é que a centralidade da ideia das instituições de ensino superior enquanto lugares de produção de cultura e ciência influenciou a forma como o corpo docente e discente da FAFI se autolocalizava. Seus membros estavam sintonizados com a ideia da universidade moderna desde seus primeiros anos. Uma carta de 1945 enviada pelo diretor interino da instituição, o professor Antônio Camilo de Faria Alvim, ao Reitor da UMG, o professor Pires e Albuquerque, apelava para a incorporação da FAFI pela UMG argumentando que a lei previa o funcionamento de uma faculdade de Filosofia nas universidades (HADDAD 1987). O próprio regimento interno da instituição estabeleceu como suas finalidades a preparação de trabalhadores intelectuais para exercer atividade de ordem desinteressada ou técnico-científica, a formação de professores, a promoção de pesquisas e a colaboração com instituições educacionais oficiais 
ou reconhecidas. ${ }^{3}$ A normatização estava em conformidade com a orientação federal que previa que o objetivo das faculdades de Filosofia era "a) preparar trabalhadores intelectuais para o exercício das altas atividades de ordem desinteressada ou técnica; b) preparar candidatos ao magistério do ensino secundário e normal; c) realizar pesquisas nos vários domínios da cultura que constituam objeto de ensino". ${ }^{4}$

Na FAFI, esses objetivos foram traduzidos por uma orientação didática que visava tanto à formação de docentes para o ensino secundário, quanto ao oferecimento de "vantagens de ordem cultural" àqueles que não pretendiam exercer funções de magistério. Em seu briefing, a instituição destacava que

não sendo uma Faculdade puramente profissional como as demais e tendo em vista principalmente realizar pesquisas desinteressadas nos vários domínios da alta cultura, da cultura desinteressada e integral, sem objetivos práticos imediatistas, precisamente por isso a Faculdade de Filosofia da Universidade de Minas Gerais prepara melhor do que nenhuma outra o chamado trabalhador intelectual, técnico ou não (KRITERION 1950).

E ainda enfatizava que "o que a Faculdade de Filosofia da Universidade de Minas Gerais visa é formar, antes de tudo, o pesquisador, o cientista, o estudioso, o letrado, isto é, o homem que faz avançar a ciência e não somente o homem que repete eternamente a ciência feita pelos outros". Numa entrevista concedida em 1988, um dos fundadores e ex-diretor da instituição, o professor Guilhermino César, afirmou que a FAFI só nasceu separada da UMG devido à falta de capacidade financeira do Estado, afastando qualquer suspeita que pudesse recair sobre sua legitimidade acadêmica (HADDAD 1988).

No espaço cultural mais amplo da cidade, a FAFI alimentou uma relação de legitimação circular: sua autoridade foi sendo conquistada na medida em que ela própria conseguia instituir socialmente a necessidade de seu produto cultural e científico (BOURDIEU 2011). A promoção de eventos (cursos, seminário e palestras) abertos a todos os interessados, a presença de professores estrangeiros e a divulgação de sua produção através da publicação de teses, separatas e monografias fomentava a vida cultural da cidade ao mesmo tempo em que garantia a autoridade para seus membros exercerem suas competências específicas. A dinâmica cultural inaugurada por essa instituição levou Cid Rabelo Horta a afirmar que a Faculdade de Filosofia foi "o maior empreendimento cultural registrado no Estado desde a fundação da Universidade em 1927" (HORTA 1953, p. 118). A criação da revista Kriterion em 1947, especialmente, teve um papel fundamental tanto para o reconhecimento social dos profissionais formados naquela faculdade, quanto para a formação de uma comunidade científica no seu interior, o que também contribuía para a sustentação da autoridade de seus membros.

\footnotetext{
${ }^{3}$ Ver REGIMENTO (1947)

4 Decreto-Lei 1.190 de 4 de abril de 1939. Dá organização à Faculdade Nacional de Filosofia. Legislação Informatizada da Câmara dos Deputados. Disponível em: www.camara.gov.br. Acesso em: 22 de ago. de 2011.
} 


\section{Francisco Iglésias e o curso de geografia e história da FAFI}

Francisco Iglésias se submeteu ao exame de vestibular (também referido como concurso de habilitação) do ano letivo de 1942 para o curso de geografia e história da FAFI. Os exames vestibulares, como processo de concurso, estavam se consolidando naquele momento como a forma privilegiada de acesso à educação superior (ALMEIDA 2006). O edital, publicado no Minas Gerais de 14 de janeiro daquele ano, enfatizava que o exame estava em conformidade com as instruções expedidas pelo Departamento Nacional de Educação (DNE). Desde 1937, havia um rígido controle do processo de acesso aos cursos da educação superior, que passou a ser regulado anualmente. Era o DNE, órgão vinculado ao Ministério da Educação e Saúde, que controlava a admissão dos candidatos aos cursos superiores e determinava o conteúdo e as datas das provas durante o Estado Novo (CUNHA 1989). As instituições de ensino superior que pleiteavam autorização oficial, como era o caso da FAFI, deveriam realizar seus concursos seguindo à risca aqueles preceitos (ALMEIDA 2006).

Embora o acesso à educação superior já estivesse sendo condicionado pela capacidade dos candidatos - o que supunha uma concorrência classificatória naquele momento, havia vagas para todos os concorrentes que alcançassem a média estabelecida para aprovação. Foram realizadas provas escritas e orais de português, cosmografia, geografia, história da civilização, sociologia e desenho, conforme as determinações federais. Todos os alunos foram aprovados e Francisco Iglésias obteve a média de 74 pontos, classificando-se em quinto lugar. Vale destacar que "essa tendência de indicar a média de aprovação se tornou uma constante nas regulamentações dos processos de acesso à educação superior, os concursos vestibulares ou concursos de habilitação", mas só foi regulamentada pelo Ministério da Educação e Saúde em 1945 (ALMEIDA 2006, p. 177).

Conforme alertou Ferreira, "[...] a temática da institucionalização da história como disciplina universitária preocupada com as concepções historiográficas, que orientaram sua criação e expansão, não tem recebido a devida atenção" (FERREIRA 2006, p. 140). Ainda que a desorganização da documentação relativa ao início da institucionalização do curso na FAFI imponha um pesado limite ao estudo deste processo, propomos traçar um esboço das concepções de história que nortearam a instalação do curso através de um estudo da grade curricular, do quadro docente e dos processos de avaliação do curso de geografia e história frequentado por Francisco Iglésias. Embora estejamos cientes de que a formação de qualquer graduando não pode ser reduzida aos aspectos protocolares de seu curso, consideramos que estas informações são significativas para a compreensão da dinâmica acadêmica na qual ele estava inserido e para a história dos cursos superiores de história no Brasil.

Conforme as determinações federais que regulamentavam o funcionamento da FNFi e que servia de modelo para a organização das demais faculdades, o curso de geografia e história da FAFI tinha duração de três anos e poderia ser acrescentado do curso de Didática, com duração de um ano. Francisco Iglésias concluiu os três anos do curso de geografia e história, obtendo o diploma de Bacharel em 1944. Na sequência, realizou sua formação pedagógica no curso de 
didática e obteve o diploma de licenciatura em 1945 (ANUÁRIO 1939-1953, p. 480-487). A grade de disciplinas cursadas por Francisco Iglésias neste período pode ser observada no Quadro 1.

Quadro 1: Grade Curricular Cursada por Francisco Iglésias (1942-1945)

\section{ANO LETIVO DE 1942}

1 a Série:
1. Geografia Física
2. Geografia Humana
3. Antropologia
4. História da Antiguidade e Idade Média

\section{ANO LETIVO DE 1943}

2a Série:
1. Geografia Física
2. Geografia Humana
3. História Moderna
4. História do Brasil
5. Etnografia

\section{ANO LETIVO DE 1944}

3a Série:

1. Geografia do Brasil

2. História Contemporânea

3. História do Brasil

4. História da América

5. Etnografia do Brasil

\section{ANO LETIVO DE 1945}

Série única de Didática:

1. Administração Escolar

2. Fundamentos Sociológicos da Educação

3. Fundamentos Biológicos da Educação

4. Didática Geral e Especial

5. Psicologia Educacional

Fonte: Currículos da Faculdade de Filosofia da Universidade de Minas Gerais (19411956); Atas de Exames da Universidade de Minas Gerais (1941-1946). Setor de Registro e Arquivo Acadêmico Permanente da Graduação da FAFICH/UFMG.

A seriação das disciplinas cursadas por Francisco Iglésias na FAFI seguia a risca a organização curricular do curso de geografia e história da FNFi. Para Ferreira e Silva, a nova nomenclatura das disciplinas imposta por esta organização - "História do Brasil" e "História da América" no lugar de "História da civilização no Brasil" e "História da civilização na América", denominações usadas na extinta Universidade do Distrito Federal - "revela uma orientação do governo Vargas de valorizar a história política nacional com a exaltação dos grandes personagens da memória nacional" (FERREIRA; SILVA 2011, p. 283-306). Ferreira ainda argumenta que: 
essa alteração, aparentemente sem maior importância, expressa, na verdade, mudanças significativas. Como já foi dito, a denominação História da Civilização expressava uma crítica a um tipo de história política comprometida com a exaltação dos grandes heróis nacionais, dos grandes eventos e datas nacionais. Em contrapartida o retorno do uso da História do Brasil representava o desfecho de uma luta anterior iniciada com a reforma Educacional de 1931, que havia instituído no ensino secundário a proposta de um novo tipo de ensino de história voltado para a valorização da dimensão cultural dos acontecimentos (FERREIRA 2006, p. 153).

Se esta tese pode ser confirmada no plano mais amplo das políticas educacionais para o ensino superior adotadas pelo governo Vargas, na análise da dinâmica das disciplinas ministradas nas salas de aula pode ser questionada. Vejamos, por exemplo, os conteúdos programados para serem aplicados nas disciplinas história do Brasil e história da América, cursadas por Francisco Iglésias em 1943 e 1944, e o conteúdo lançado pelos professores nos diários destas disciplinas. Ainda que este tipo de fonte não permita verificar até que ponto os programas foram de fato implementados, tampouco se as matérias lecionadas declaradas nos diários refletem a prática da sala de aula, a documentação indica quais os modelos para o ensino de história estavam sendo considerados no momento em que este campo disciplinar emergiu no ensino superior mineiro.

Desde a sua fundação, o professor catedrático de história do Brasil na Faculdade de Filosofia de Minas Gerais era Antônio Camilo de Oliveira Alvim. ${ }^{5}$ Quando Francisco Iglésias cursou a matéria, na segunda e na terceira série, a cadeira estava ocupada por João Camilo de Oliveira Torres, ${ }^{6}$ professor contratado de ética. A partir da análise do programa da disciplina e do conteúdo lançado nos diários de classe podemos observar que as matérias eram bastante diversificadas e, de nenhuma maneira, se resumiam aos grandes nomes e eventos da história nacional. ${ }^{7}$

$\mathrm{Na} 2^{\mathrm{a}}$ série, o programa de história do Brasil do curso de geografia e história em Minas Gerais previa o estudo da historiografia brasileira desde os cronistas dos tempos coloniais, passando pelas obras de Varnhagem e Capistrano de Abreu, até o que se chamou de "os modernos historiadores". A unidade também incluía pontos sobre "a pesquisa e a cultura histórica no Brasil", o que demonstrava uma preocupação com as questões que permeavam o ofício de historiador. Paralelamente aos temas recorrentes da história política organização social e política de Portugal, expansão marítima e os descobrimentos

\footnotetext{
${ }^{5}$ Formado em Direito pela Universidade de Minas Gerais, Antônio Camilo de Faria Alvim exerceu os cargos de deputado estadual, prefeito de Itabira e de promotor de Justiça de Belo Horizonte. Foi diretor da Faculdade de Filosofia da UMG por três vezes e entre suas atividades pedagógicas constava em seu currículo, além do cargo de professor de história do Brasil da Faculdade de Filosofia da UMG desde a fundação, os cargos de professor de história do Brasil da Escola Normal Oficial de Itabira, de professor de educação cívica da Escola Normal de Itabira e de examinador em concurso de história e de geografia do Colégio Estadual de Belo Horizonte (ANUÁRIO 1939-1953, p. 318).

6 João Camilo de Oliveira Torres fez o curso superior de Filosofia na Faculdade de Filosofia da Universidade do Distrito Federal e, além da Faculdade de Filosofia da UMG, lecionou também na Faculdade de Filosofia, Ciências e Letras Santa Maria, de Belo Horizonte. Membro do Instituto Histórico e Geográfico de Minas Gerais e da Academia Mineira de Letras, publicou O sentido e a finalidade do ensino universitário (1940), O positivismo no Brasil (1943), O homem e a montanha (1944), entre outros (ANUÁRIO 1939-1953, p. 386).

7 Os programas das cadeiras do curso de geografia e história da FAFI, bem como os diários de classe das disciplinas se encontram no Setor de Registro e Arquivo Acadêmico Permanente da Graduação da FAFICH/UFMG.
} 
- o programa previa um tópico sobre a "intencionalidade do descobrimento" do Brasil e sobre os aspectos etnográficos e linguísticos da Carta de Caminha. Entre os fatores relacionados à colonização portuguesa no Brasil, constava uma unidade sobre o elemento indígena que incluía um estudo sobre "o indígena na formação da família brasileira", e outra sobre o elemento negro que contemplava o conhecimento das áreas culturais do negro na África e "o papel do negro na civilização brasileira".

A notável influência das obras de Gilberto Freyre pode ser percebida na unidade sobre "a sociedade patriarcal" que incluía tópicos sobre "a casa, o mobiliário e as alfaias coloniais", "a indumentária e a alimentação nos tempos coloniais" e a "decadência do patriarcado rural". A influência dos estudos de outro "historiador moderno", Sérgio Buarque de Holanda, pode ser notada na unidade sobre a "formação dos centros urbanos", com tópicos sobre os "fatores de formação das primeiras povoações", os "centros iniciais da vida colonial" e o "esplendor e decadência das cidades coloniais". Uma unidade sobre a "evolução cultural" brasileira também estava prevista no programa, com tópicos sobre "a língua e a literatura", "as artes e as ciências", "as expedições científicas" e "o ensino e a educação" no Brasil colonial.

Na $3^{a}$ série do curso, o programa da cadeira de história do Brasil previa o estudo da história brasileira a partir da transmigração da família real portuguesa e a abertura dos portos até o processo de industrialização na República. Além da ênfase na política interna e externa do Império e da República, as unidades de 116 estudo contemplavam a evolução cultural e social dos períodos com tópicos sobre "a educação e o ensino", "as letras ciências e artes" e "a vida social e religiosa".

A cadeira de história da América também era feita na $3^{a}$ série do curso de geografia e história e o professor da disciplina desde 1944, responsável por seu programa, era José Albano de Morais. ${ }^{8}$ A turma de Francisco Iglésias, no entanto, ainda que tenha feito a cadeira neste ano, teve como professor o escritor Sebastião de Oliveira Salles, cujo nome sequer consta na relação do corpo docente da faculdade. A matéria lecionada por ele consta no diário e indicia que o programa do professor José Albano de Morais que é apresentado no Anuário de 1939 a 1953 já era uma referência para a turma de Francisco Iglésias.

O programa da cadeira previa uma introdução com noções gerais, como a "posição da história da América no curso de geografia e história", a "orientação filosófica da cadeira" e o "conhecimento da América na antiguidade". No estudo sobre a pré-história americana estava prevista a apresentação das várias hipóteses sobre a origem do homem americano e uma reflexão sobre "a cultura de grãos não panificáveis como fundamento econômico das primitivas civilizações americanas e suas consequências". Paralelamente aos fatos políticos do descobrimento da América, no programa constava o estudo sobre "a ciência

\footnotetext{
${ }^{8}$ Inspetor Federal do Ensino Superior junto à Faculdade de Filosofia da UMG, José Albano de Morais assumiu a cadeira de História da América em 1944 e foi nomeado catedrático em 1949. Formado em Direito pela UMG, ele foi professor de história geral, história do Brasil e história da América no Colégio Marconi entre 1937 e 1950 e era examinador oficial no concurso para professor de geografia e de história na Escola Técnica de Belo Horizonte (ANUÁRIO 1939-1953. p. 366-367).
} 
e a técnica no descobrimento da América" e sobre os grandes impérios pré-colombianos com tópicos sobre os usos e costumes dos Astecas e Incas e sobre "a vida religiosa, econômica, social e moral dos primitivos povos americanos", incluindo a exposição de temas sobre os sacrifícios humanos, as artes e as fontes da história dos povos pré-colombianos. Além de contemplar as lutas econômicas do século XVII, o programa também propunha uma "comparação entre os sistemas coloniais inglês e espanhol" - incluindo estudos sobre a organização social, o movimento migratório, o problema do índio - e uma reflexão sobre "as teorias políticas e a prática colonial". Além dos movimentos de independência do século XVIII e da história da América livre no século XIX, o programa incluía o estudo da história dos Estados Unidos e de suas relações hostis com os países latino-americanos, bem como a exposição da América no cenário político mundial.

Portanto, o modelo para a constituição das cadeiras de história do Brasil e de história da América do curso de geografia e história da FAFI estava inspirado por um conteúdo considerado "inovador" de história social e por aquilo que havia de mais moderno na historiografia do período. A abertura de cursos de geografia e história a partir das diretrizes impostas pela organização da FNFi não significou, necessariamente, sua inscrição em um projeto de história nacional afeita à exaltação de grandes nomes e datas. Se a institucionalização do curso de história na FNFi foi, como afirmou Ferreira,

fortemente influenciada por uma concepção de história afinada com as regras do Instituto Histórico e Geográfico Brasileiro, onde predominava a concepção de uma história política destinada a reforçar os laços da identidade nacional brasileira através do fortalecimento da unidade nacional e do papel dos grandes heróis como construtores da nação (FERREIRA 2006, p. 156).

O caso de Minas Gerais parece não ter acompanhado totalmente esta regra. Se a organização administrativa e curricular da Faculdade de Filosofia seguia as formalidades do curso da FNFi, a concepção de história que a norteava apresentava traços mais complexos.

Vejamos, por exemplo, uma prova da cadeira de história do Brasil realizada por Francisco Iglésias em 1943. Diante da questão "quem foi Américo Vespúcio?", cuja elaboração foi orientada pela exaltação de um grande personagem histórico, o estudante escreveu o seguinte:

\footnotetext{
Existe, no plano da história literária como da História em geral, o drama do desencontro entre a publicidade, o grande nome de uma figura e o seu papel real. Autores há que apenas influenciaram, abrem caminhos, propõem os temas, mas não realizam uma obra; sua influência é profunda, mas subterrânea; não aparecem nunca; são como a agulha do apólogo famoso de Machado de Assis.

Vejamos o caso de Vespucci; as suas gerações e os pósteros glorificaram-Ihe o nome; conhecido e festejado por todos, deu o seu nome ao continente descoberto por Colombo em $1492[\ldots]{ }^{9}$
} 
E, depois de traçar a trajetória do navegante florentino inserindo-a no contexto mais amplo das relações entre a América e a Europa, Francisco Iglésias concluiu que a ênfase naquele grande nome presente nas páginas dos livros de história não correspondia à nova interpretação que estava sendo dada aos seus feitos: "Diante do que fez, merecia tamanha importância? Parece-nos que não. Américo Vespucci representa mais um caso de injusta distribuição de glória". ${ }^{10}$ Avaliada por três examinadores, todos professores da instituição, a resposta à questão recebeu, unanimemente, a nota máxima, o que indica a concordância com o ponto de vista crítico em relação à própria concepção de história que orientou a formulação da questão.

\section{Francisco Iglésias e as representações do curso de história}

Em uma entrevista de 1991, quando questionado a respeito da influência que a FAFI teve sobre sua atividade como historiador, Francisco Iglésias lamentou não poder falar de nenhum professor seu com a reverência com que os ex-alunos das faculdades de Medicina e de Direito falavam de seus professores (SBPC 1991). Com efeito, enquanto os cursos superiores considerados tradicionais existiam em Minas Gerais desde a passagem do século XIX para o XX, o curso de história no qual Francisco Iglésias se graduou foi criado apenas na década de 1940. Durante toda a sua formação, a FAFI funcionou sem o reconhecimento federal, que só aconteceu em 1946, e sofreu com a falta de estrutura e com a "improvisação" de seu corpo docente. Esta desestabilização se fez refletir nas

118 turmas do curso de geografia e história que se formaram entre 1946 a 1948: em cada ano, saíram apenas dois diplomados (ANUÁRIO 1939-1953).

Mas esta não foi uma exclusividade mineira. Nos depoimentos de grandes historiadores de outros estados é recorrente a observação da carência de profissionais especializados nos cursos de história das universidades, mesmo naquelas institucionalmente reconhecidas. A avaliação negativa dos professores foi feita pelos contemporâneos de Francisco Iglésias formados na USP, na UDF ou na Universidade do Brasil. A professora Emília Viotti da Costa, por exemplo, que ingressou na USP em 1948, ponderou que não teve professores marcantes no curso de história e que teria sido mais influenciada pelos livros que leu e por professores de outros departamentos do que pelos do departamento de história. Ela também revelou que, na prática, pelo menos até a década de 1950, a pesquisa não fazia parte da formação dos futuros professores naquela instituição (MORAES; REGO 2002, p. 70).

Os programas das cadeiras do curso de geografia e história da FAFI na grade curricular de 1939 a 1953 mostram que aqui também quase não havia espaço para discussões teórico-metodológicas (ANUÁRIO 1939-1953). Mesmo alguns anos mais tarde, em 1957, quando o curso de história foi separado do curso de geografia, o currículo foi considerado "arcaico", "tradicional" e "pobre" por quem o cumpriu (RESENDE 1991, p. 20). A faculdade de filosofia continuava a ser

10 Prova de história do Brasil realizada por Francisco Iglésias em 7 de julho de 1943. Setor de Registro e Arquivo Acadêmico Permanente da Graduação da FAFICH/UFMG. 
voltada para a preparação de professores e, embora pudesse ser desqualificada por quem demandava investimento em pesquisas, ela parece ter cumprido satisfatoriamente a demanda social por docentes para o ensino secundário, pois o salto de qualidade da escola secundária foi por todos notada. Para Resende, o que garantia essa excelência era a unificação dos corpos docentes do ensino superior e secundário. Segundo ela, "o interesse pela docência na escola pública, superior ou secundária, tinha na cátedra, instituição comum aos dois níveis, um ponto de alta correlação, que a tornava atraente ao exercício profissional" (RESENDE 1991, p. 23).

Outro crítico dos primeiros anos dos cursos universitários de história foi Edgar Carone, formado na USP em 1948. Ele lembrou que teve bons professores franceses, mas "também tive alguns pernas de pau". Após a sua formatura, seu dilema era "vou lecionar ou vou para a fazenda?", pois sua formação não permitia outra coisa. Decidiu-se pela fazenda, onde permaneceu por 12 anos ininterruptos (MORAES; REGO 2002, p. 51). Também Maria Yedda Leite Linhares teve impressão parecida sobre a UDF e a Universidade do Brasil, onde ingressou em 1939. Ela destacou negativamente seus professores de história, sugerindo que "talvez nem devam ser lembrados" (MORAES; REGO 2002, p. 26).

As avaliações negativas dos cursos e dos professores dos departamentos de história foram comuns àquela geração pioneira que fez carreira na universidade. Mas elas precisam ser consideradas a luz do contexto em que foram feitas, pois os critérios de verificação para determinar a qualidade dos cursos estavam informados por uma realidade alheia àquela que estava sendo posta à prova. $\mathrm{Na}$ década de 1940, quando esses historiadores se formaram, o que era considerado "inovador" ou "tradicional" no conhecimento histórico se distanciava bastante daquilo que orientava suas avaliações nas décadas de 1990 e 2000.

Em uma nota publicada em 1944, por exemplo, ao comentar o livro de seu professor no curso de geografia e história da FAFI - João Camilo de Oliveira Torres - Francisco Iglésias destacou "a importância do trabalho e do seu autor", cujo livro sobre o papel da geografia de Minas Gerais na constituição de grupos sociais "ninguém deixará de consultar no futuro para o estudo do nosso Estado". Ele afirmou ainda que, através de seus livros, "João Camilo mostra a sua extraordinária cultura, o conhecimento que tem de toda a filosofia moderna e da história do Brasil" (IGLÉSIAS 1944).

Em artigo de 1956, Francisco Iglésias destacou positivamente outro professor da FAFI - Arthur Versiani Velloso - catedrático de história da filosofia. Reconheceu a importância da iniciativa deste professor junto ao grupo fundador da instituição em um momento em que "não se cuidava do assunto". Por ocasião do seu aniversário de 50 anos, Francisco Iglésias foi convidado para escrever sobre o antigo professor e se colocou entre os alunos da FAFI que Ihe deviam atenção e favores. Dele, Francisco Iglésias destacou a experiência docente, enfatizando que ainda lembrava as lições do professor: "ainda hoje lembramos esses companheiros antigos e eu, essas lições como eram dadas, o que era dado, bem como fatos circunstanciais dignos de memória para nós" (IGLÉSIAS 1956, p. 4). 
Portanto, a avaliação negativa que Francisco Iglésias fez de seu curso e de seus professores deve ser compreendida como parte do contexto discursivo que integrou as demandas da reforma universitária de 1968 e sua definição a respeito das atribuições docentes e da própria função social da universidade. 0 tom denunciatório da condição supostamente precária dos cursos de história em suas fases iniciais está associado à construção de um discurso posterior sobre o que seria uma organização adequada à realidade universitária. Os depoimentos de Francisco Iglésias e de seus contemporâneos estavam informados pelas exigências da época em que foram declarados, daí julgarem que o despreparo de seus professores impediu que o curso de história cumprisse a contento o seu propósito de formar profissionais da área. Mas, apesar da primeira geração de historiadores formados pelas universidades terem tido uma formação orientada pelos chamados "não especialistas" - portanto, "não profissionais", "amadores" - que ainda ocupariam as principais cadeiras do curso de história na universidade durante longos anos, eles adquiriram a legitimidade social necessária para se tornarem "verdadeiros" historiadores.

\section{Referências bibliográficas}

ALMEIDA, Silvia Maria Leite de. Acesso à educação superior no Brasil: uma cartografia da legislação de 1824 a 2003 [Tese em Educação]. Porto Alegre: Universidade Federal do Rio Grande do Sul, 2006.

ANUÁRIO da Faculdade de Filosofia da Universidade de Minas Gerais. Belo Horizonte, 1939-1953.

ARAUJO, Valdei Lopes. Cairu e a emergência da consciência historiográfica no Brasil (1808-1930). In: NEVES, Lucia M. B. Pereira das et all (org.). Estudos de historiografia brasileira. Rio de Janeiro: FGV, 2011.

BLANKE, Horst Walter. Para uma nova história da historiografia. In: MALERBA, Jurandir (org.). A história escrita: teoria e história da historiografia. São Paulo: Contexto, 2006.

BOURDIEU, Pierre. Os usos sociais da ciência: por uma sociologia clínica do campo científico. São Paulo: UNESP, 2004.

Homo academicus. Florianópolis: UFSC, 2011.

CERTEAU, Michel de. A escrita da história. Rio de Janeiro: Forense Universitária, 2008.

CUNHA, Luiz Antônio. A universidade crítica: o ensino superior na República Populista. Rio de Janeiro: Francisco Alves, 1989.

DIEHL, Astor Antônio. A cultura historiográfica brasileira: década de 1930 aos anos 1970. Passo Fundo: UPF Editora, 1999.

FERREIRA, Marieta de Moraes. Notas sobre a institucionalização dos cursos universitários de história no Rio de Janeiro. In: GUIMARÃES, Manoel Luiz Salgado (org.). Estudos sobre a escrita da história. Rio de Janeiro: 7Letras, 2006. 
FERREIRA, Marieta de Moraes; SILVA, Norma Lúcia da. Os caminhos da institucionalização do ensino superior de história. História \& Ensino, Londrina, v. 2, n. 17, jul./dez. 2011.

FOUCAULT, Michel. A ordem do discurso. São Paulo: Loyola, 2003.

FRANZINI, Fábio; GONTIJO, Rebeca. Memória e história da historiografia no Brasil: a invenção de uma moderna tradição, anos 1940-1960. In: SOIHET, Rachel et all (orgs.). Mitos, projetos e práticas políticas: memória e historiografia. Rio de Janeiro: Civilização Brasileira: 2009.

GUIMARÃES, Manoel Luiz Salgado. Entre amadorismo e profissionalismo: as tensões da prática histórica no século XIX. Topoi, Rio de Janeiro, dez. 2002.

HABERMAS, Jürgen. A ideia da Universidade: processos de aprendizagem. Revista de Educação, Lisboa, vol. 2, 1987.

HADDAD, Maria de Lourdes Amaral. Faculdade de Filosofia de Minas Gerais: raízes da ideia de universidade na UMG [Dissertação de Mestrado]. Belo Horizonte: Faculdade de Educação da UFMG, 1988.

HORTA, Cid Rabello. A Faculdade de Filosofia, núcleo da Universidade de Minas Gerais. Revista da Universidade de Minas Gerais, n. 10, maio de 1953.

IGLÉSIAS, Francisco. João Camilo de Oliveira Torres. A manhã. Belo Horizonte, 16 de junho de 1944.

. Um professor de entusiasmo. O Diário. Belo Horizonte, 22 de janeiro de 1956.

JULIA, Dominique. A cultura escolar como objeto histórico. Revista Brasileira de História da Educação, Campinas, n. 1, jan./jun. 2001.

KRITERION, Belo Horizonte, no 13-14, jul-dez, 1950.

MORAES, José Geraldo Vinci de; REGO, José Márcio. Conversas com historiadores brasileiros. São Paulo: Editora 34, 2002.

NOVAIS, Fernando. A Universidade e a pesquisa histórica: apontamentos. Estudos Avançados, São Paulo, v. 4, n. 8, jan./abr. de 1990.

REGIMENTO da Faculdade de Filosofia de Minas Gerais, cópia 1947, Setor de Registro e Arquivo Acadêmico Permanente da Graduação da FAFICH/UFMG.

RESENDE, Maria Efigênia Lage de. Memorial. Belo Horizonte: UFMG, 1991

ROIZ, Diogo da Silva. Dos "discursos fundadores" à criação de uma "memória coletiva": formas de como se escrever a(s) história(s) da Universidade de São Paulo. Revista Brasileira de História da Educação, n. 19, jan./abr. 2009.

SBPC. Cientistas do Brasil: depoimentos. São Paulo: Global, 1991.

WEHLING, Arno. Historiografia e epistemologia histórica. In: MALERBA, Jurandir (org.). A história escrita: teoria e história da historiografia. São Paulo: Contexto, 2006. 